\title{
The Global Trade of Textiles and Clothing in the Early Modern Period: Exchange, Meaning and Materialities
}

\author{
International PhD and Postdoctoral Workshop, 27-28 \\ November 2014, University of Warwick
}

Karolina Hutkova*

Department of History, University of Warwick, Coventry, UK

*Correspondence: k.hutkova@warwick.ac.uk

\begin{abstract}
The two-day workshop at the University of Warwick brought together early career researchers studying various aspects of textile history - production, consumption, trade, fashion, and design - with the aim of drawing broader conclusions about the role of textiles and clothing in the development of societies, cultures and economies. The methodological and geographical breadth of the presented research holds a promise that in the near future we will be presented with a much more global picture of textile production, consumption and trade in the early modern period.
\end{abstract}

Keywords: material culture, social history, economic history, textiles, trade, consumption, production.

(C) Copyright: The Authors. This article is issued under the terms of the Creative Commons Attribution NonCommercial Share Alike License, which permits use and redistribution of the work provided that the original author and source are credited, the work is not used for commercial purposes and that any derivative works are made available under the same license terms.

\section{The Global Trade of Textiles and Clothing in the Early Modern} Period: Exchange, Meaning and Materialities

What is the value of researching textiles? Do they really have any research potential? How much can textiles or objects in general tell us about the past? Should we be focusing on such ephemeral and perishable things as textiles? Are textiles more than beautiful artefacts? I argue that, yes, textiles are much more than merely pretty objects and the Warwick workshop showed the research potential of textiles. 


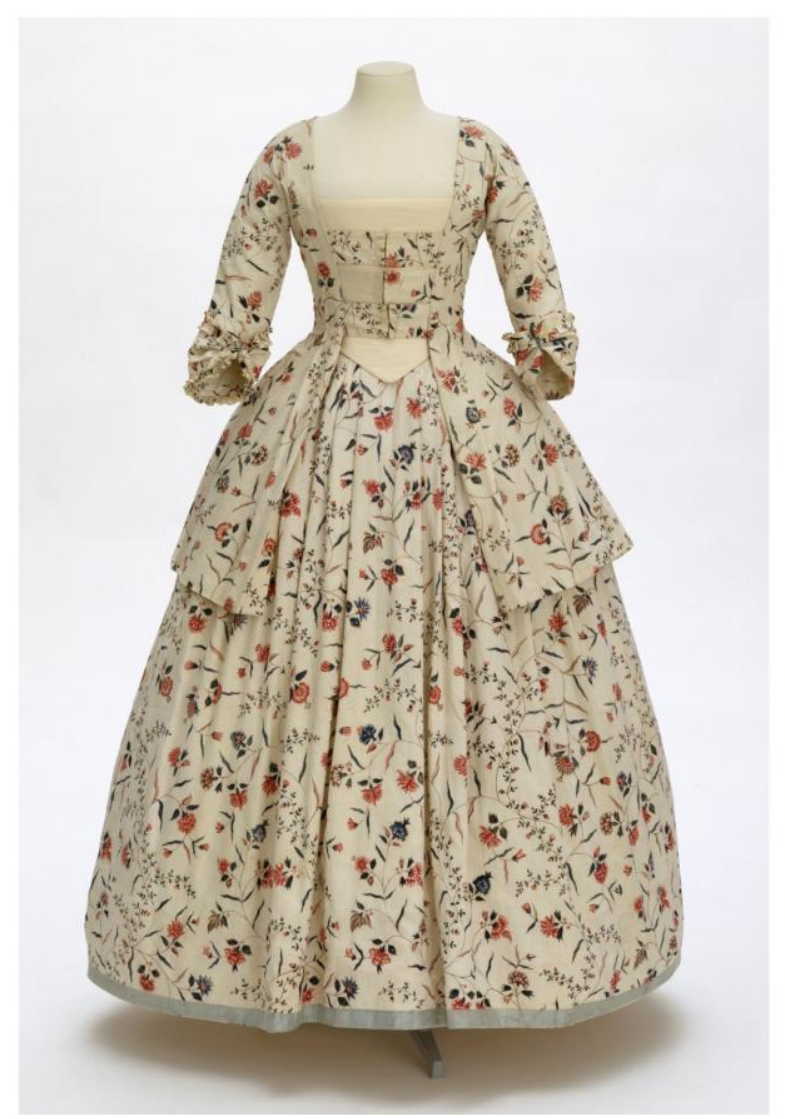

V\&A Museum South Asia, T.229\&A-1927, Caraco and Petticoat, Coromandel Coast, India (fabric, made), England, Great Britain (tailored), 1770-1780, @ V\&A Museum London

Throughout history, textiles have played an important role among the objects that surrounds us. The use of textiles is close to everyone's daily life; they are represented in the environment of our homes, and clothes textiles are close to our body and accompany us through life. Therefore, the patterns of production, consumption and trade with fabrics can tell us a lot about the development of historical as well as current societies. For instance, the Lancashire mills and the development of the cotton industry in Britain is inseparably tied to the First industrial revolution. Furthermore, the development of textile industries was linked with the first wave of industrialization in many countries in Europe and Asia.

Currently, the development of textile industries represents an important source of employment opportunities in Asia and Africa. At the same time, conditions in textile production feature prominently in anti-sweatshop campaigns and illustrate the social implications of our current consumption habits. These are just the highlights, showing the ways in which textiles illustrate the development of human societies, economies and cultures. Considering that there are various methodologies that can be applied to the study of objects, the task of 'telling history through things' should not be left only to museums (MacGregor, 2010: xiii). With 
this objective in mind, the workshop at the University of Warwick aimed to present new research done in the various areas of textile history.

Study of textiles and their production, consumption and representation is a long established field. Textiles are generally approached from the methodological perspective of either material culture, economic history or the history of arts, the aim of this workshop was thus to bridge such a divide by giving space to papers representing a wider spectrum of approaches. The intention was also to cover a wider geographical area and bring together early career researchers from various institutions around the world. The want of current scholarship is the prevailing focus on Northwestern Europe, especially Britain, and Southern Europe, particularly Italy. Comparatively less research is available on central Europe, Africa, and Latin America, moreover until recently even the research on Asia was focused predominantly on production for the European markets. The workshop therefore also aimed to present a more global approach to the early modern textile history.

The workshop brought together nearly 40 academics and researchers from several institutions from around the world. The initiative to hold a workshop resulted from an international collaboration with the Centre for Textile Research at the University of Copenhagen and the workshop became one in a series of workshops of the Costumes, Clothing, Consumption and Culture research programme that brings together researchers focusing on early modern textile history. In order to widen the research network and to promote global approach to the study of history and culture, through the exploration of connections and interaction - as is the mission of the Global History and Culture Centre at the University of Warwick - we announced an open call for papers.

Global history is still a less well-established historiographical tradition but through its focus on connection and interaction and/or comparisons, it is particularly valuable for the study of early modern textile production, consumption and trade. Textile history is a field with immense 'potential to construct negotiable meta-narratives' cosmopolitan in outlook and fit for the study of interconnected and globalizing world, to paraphrase Patrick O'Brien (2006: 3), professor of global economic history. Textiles were the first to overcome the 'tyranny of distance' through connections in the form of trade with raw materials - intermediary as well as finished products - design and fashion influences. Technological and knowledge exchanges can be traced at least to the early modern period in textile history (Braudel, 1981: 415-30).

The papers presented at the workshop covered a breadth of geographical areas, ranging from different parts of Europe, to the Ottoman Empire, Africa and Asia. Importantly, the papers also highlighted connections 
between these parts of the world. The particular contribution of the workshop was in the number of presentations that focused on these sparsely studied connections. For instance, Jutta Wimmler (European University of Viadriana, Frankfurt) in her presentation highlighted the vital role of gum arabic produced in West Africa for European textile production. Gum arabic from Senegal was imported to France and used in medicine, ink, watercolour and glass painting, perfume, and in the leather and dyeing industries. However, as Wimmler argued, the role of gum arabic was particularly important in dyeing in $18^{\text {th }}$ century Europe as the low price of the gum made possible the production of large quantities of calicoes for cheap prices. Another example of intercontinental exchange was presented by Stefania Montemezzo (University of Bologna), who reconstructed the commodity chain created between Venice and Ottoman Empire in $15^{\text {th }}$ century in production of woollens. Montemezzo presented a case study of a Venetian firm that was importing olive oil as well as other products to Alexandria, buying woollen cloth in the Ottoman Empire from the profits and importing the cloth to Venice where it was dyed, finished, and customised. The finished product was sold in Venice, as well as being exported.

Several presentations focused on Africa. For instance, connections between Africa and India were explored by Kazuo Kobayashi (London School of Economics) who argued that the African demand for cottons was shaping production in India. Kobayashi argued that demands for improved quality of blue goods or guinea cloth in Senegambia and Upper Guinea was among the factors that drove the English East India Company (EEIC) to attempt to change the system of procurement of textiles in South India in $18^{\text {th }}$ century. Overall, the presentations focusing on Africa signified a shift from perceiving Africa through the lens of triangular trade to attributing agency to Africans. Such a shift was particularly noticeable in Katherine Frederick's (Wageningen University) presentation that explored textile production in Nyasalaand in SouthEastern Africa. Similarly, Benjamin Jody (Harvard University) pointed out that West African merchants played a very active role in building global trade linkages between Asia, Africa and America.

Another geographical area sparsely covered by the current scholarship is central Europe. In this respect the workshop offered papers that are part of larger projects focusing on integrating central Europe into the wider networks of global production and trade. Gabi Schopf (University of Bern) presented a paper on the Swiss printing company Laué \& co. Switzerland was an important centre of textile production in early modern Europe, however there are few studies in the English language. Schopf showed that by relying on travelling salesmen, Laué \& co. was able to produce customised textiles for French, Dutch and Italian 
markets. The presentation of Anka Steffen (European University of Viadriana, Frankfurt) also illustrated how highly interconnected the European textile market was in $17^{\text {th }}$ and $18^{\text {th }}$ century by looking at the business networks of Silesian merchants.

Apart from exploring diverse geographical areas, the research presented at the workshop showed breadth of methodological approaches. Several papers relied methodologically on approaches of social and economic history. Chris Niestrasz (University of Warwick) and Vibe Martens (EUI) applied quantitative and qualitative approaches, respectively, to studies of impacts of imports of Indian-produced textiles on the Dutch, English and Danish economies and societies. Other methodologies included studies of objects. For instance, Gwendolyn Collaco (Harvard University) explored the role of costume albums which captured clothing of the Ottoman court in creating a perception of Ottoman fashions and identity in Europe. Emma Rogers (Courtalds Institute, V\&A) studied quilts in the V\&A collections and showed how these Indian-produced textiles incorporated European motifs and designs. Similarly, the keynote speaker, Barbara Karl, a curator at Museum of Applied Arts Vienna (MAK), focused on Indian embroideries that made their way to Europe and are now to be found in various European museums. Karl analysed the complexities of international exchange of designs between Europe, especially Portugal, and Bengal and Gujarat in India. She reasserted the importance of adaptations of Indian designs to European tastes for creating demand for Indian embroideries in Europe.

As the main success of the workshop, I consider that the event brought together new researchers from a number of institutions focusing on diverse geographical areas and applying various methodologies. The fact that such a gathering could happen shows the shift in the discipline of textile history. New research produced in the area of textile history seems much more interdisciplinary and open to new approaches and not so rigorously focused on one methodological approach only - whether social, economic, art history or a material culture - without the ability to incorporate other methodologies. Second, the presented papers illustrated that areas which were previously at the periphery of research interest are now attracting attention. This shift is important for two reasons. First, since textile production, consumption and trade were creating connections between different parts of the globe already in the early modern period, it is important to follow all these connections in order to create a more holistic picture of the early modern world. Second, incorporating new regions and studying the patterns of textile production, consumption and trade in these regions will also assist us in reassessing the existing scholarship on widely researched regions. It could help to trace global patterns and to find outliers. 
Assuming that the research presented at the workshop is representative of the new research that is being generated in the field of textile history, the future promises to bring interesting new additions to the existing historiography. It will be interesting to follow the many new research projects and wait for the results that they will bring. Since sharing of ideas and results of research on the international level is essential for generating new scholarship, workshops such as the one organised at the University of Warwick are key in facilitating such interchange of ideas.

\section{Acknowledgements}

The Global Trade of Textiles and Clothing in the Early Modern Period: Exchange, Meaning and Materialities was generously sponsored by the Centre for Textile Research at the University of Copenhagen, by the Economic History Society, by the Global History and Culture Centre at the University of Warwick and by the Department of History at the University of Warwick. It was organised jointly by Costumes, Clothing, Consumption and Culture (CCCC) - The Danish National Foundation's Centre for Textile Research, University of Copenhagen and the Global History and Culture Centre, University of Warwick and it became the fourth workshop of the cCCC network.

\section{References}

Braudel, F. (1981). Civilization and Capitalism, $15^{\text {th }}-18^{\text {th }}$ Century: The Structures of Everyday Life, vol. 1, London: Collins

MacGregor, N. (2010). History of World in 100 Objects, London: Allen Lane

O’Brien, P. (2006). 'Historiographical Traditions and Modern Imperatives for the Restoration of Global History', Journal of Global History 1 (1): 3-39

\section{Illustrations}

V\&A Museum South Asia, T.229\&A-1927, Caraco and Petticoat, Coromandel Coast, India (fabric, made), England, Great Britain (tailored), 1770-1780, with the kindly permission of (C) V\&A Museum London 
To cite this article:

Hutkova, K. (2015). The Global Trade of Textiles and Clothing in the Early Modern Period: Exchange, Meaning and Materialities. Exchanges: The Warwick Research Journal, 2(2), 314-320. Retrieved from:

http://exchanges.warwick.ac.uk/index.php/exchanges/article/view/58 